\title{
Pengembangan Kapasitas Teknologi Informasi Pegawai Kanwil DJP Jakarta Selatan II Melalui Pelatihan Ms. Excel Tingkat Dasar
}

\author{
Samsinar*, Titin Fatimah, Dolly Virgian Shaka Yudha Sakti, Pipin Farida Ariyani \\ Fakultas Teknologi Informasi, Universitas Budi Luhur \\ *Email Corresponding: samsinar@budiluhur.ac.id
}

\begin{abstract}
ABSTRAK
Tidak semua staf yang bekerja di bawah DJP Jakarta Selatan II memiliki tugas yang wajib bersentuhan dengan teknologi. Sehingga banyak dari staf tersebut yang membutuhkan penyegaran terhadap pengetahuan terkait teknologi, khususnya tentang MS Excel tingkat dasar. Mitra PPM sangat membutuhkan beberapa hal diantaranya membutuhkan penyegaran kembali pengetahuan tentang Microsoft Excel tingkat dasar. Pelatihan Microsoft Excel tingkat dasar menjadi solusi untuk dapat menyegarkan kembali pengetahuan para staf yang dimiliki mitra terkait Microsoft Excel tingkat dasar.
\end{abstract}

Kata Kunci: Pelatihan Excel, Excel Dasar, Penyegaran Excel

\section{PENDAHULUAN}

Direktorat Jenderal Pajak(DJP) merupakan salah satu instansi pemerintah yang mempunyai peran penting dalam penerimaan negara. Organisasi DJP memiliki jumlah kantor operasional lebih dari 500 unit kantor dan lebih dari 45.000 pegawai yang tersebar di seluruh penjuru tanah air. DJP merupakan Unit Eselon I terbesar di Kementerian Keuangan (Direktorat Jenderal Pajak, 2019). Tugas dan fungsi DJP dilaksanakan dalam pencapaian visi DJP yang ditetapkan, yaitu: "Menjadi institusi penghimpun penerimaan negara yang terbaik demi menjamin kedaulatan dan kemandirian negara" dengan memperhatikan misi DJP yaitu Menjamin penyelenggaraan negara yang berdaulat dan mandiri dengan: (a) Mengumpulkan penerimaan berdasarkan kepatuhan pajak sukarela yang tinggi dan penegakan hukum yang adil, (b) Pelayanan berbasis teknologi modern untuk kemudahan pemenuhan kewajiban perpajakan, (c) Aparatur pajak yang berintegritas, kompeten, dan profesional, (d) kompensasi yang kompetitif berbasis sistem manajemen kinerja.

Kantor Wilayah DJP Jakarta Selatan adalah unit vertikal Direktorat Jenderal Pajak di daerah yang membawai beberapa Kantor Pelayanan Pajak Pratama dan sebuah Kantor Pelayanan Pajak Madya. Sejalan dan searah dengan reformasi di Direktorat Jenderal Pajak, demikian juga yang terjadi di Kanwil DJP Jakarta III. Sesuai dengan keputusan Menteri Keuangan Nomor: 519/KMK.01/2003 tanggal 2 Desember 2003 tentang Perubahan atas Keputusan Menteri Keuangan Nomor: 443/KMK.01/2001 tentang Organisasi dan Tata Kerja Kantor Wilayah Direktorat Jenderal Pajak, Kantor Pelayanan Pajak, KPPBB, Karikpa yang mengubah Kanwil DJP Jakarta III yang meliputi Kotamadya Jakarta Selatan dengan unit kantor operasional meliputi 10 Kantor Pelayanan Pajak, 3 Kantor Pelayanan Pajak Bumi dan Bangunan, dan 2 Kantor Pemeriksaan Pajak menjadi 1 Kantor Madya Jakarta Selatan dan 12 Kantor Pelayanan Pajak Pratama. 


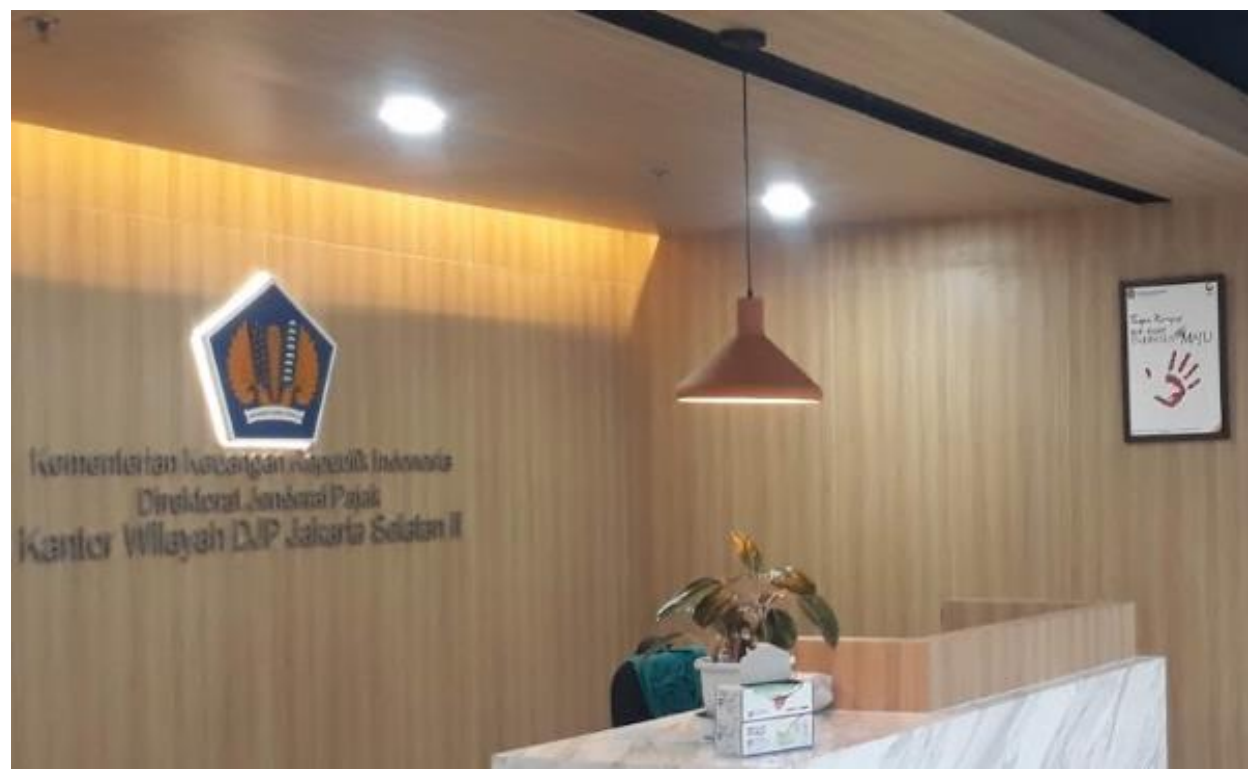

Gambar 1. Kantor Wilayah DJP Jakarta Selatan II

Sistem pelayanan yang ada di DJP saat ini sudah mulai menggunakan sistem elektronik seperti e-filing. Adanya sistem elektronik perlu didukungan semua pihak agar pelayanan wajib pajak dan kepatuhan wajib pajak terus mengalami peningkatan agar tercapainya administrasi perpajakan yang baik dan modern(Rysaka, Saleh, \& Rengu, 2014). Tidak semua staff yang bekerja di bawah DJP Jakarta Selatan II memiliki tugas yang wajib bersentuhan dengan teknologi. Sehingga banyak dari staff tersebut yang membutuhkan penyegaran terhadap pengetahuan terkait teknologi, khususnya tentang Microsoft Excel tingkat dasar (Wardani, 2017). Sejalan dengan misi DJP dalam hal "pelayanan berbasis teknologi modern untuk kemudahan pemenuhan kewajiban perpajakan" dan "aparatur pajak yang berintegritas, kompeten, dan profesional" maka DJP berkeinginan menyegarkan kembali pengetahuan para staff tersebut.

Staff yang membutuhkan penyegaran Microsoft Excel diantaranya staff yang ada di Kanwil Jakarta Selatan II, KPP Pratama Jakarta Kebayoran Baru Satu, KPP Pratama Jakarta Kebayoran Baru Dua, KPP Pratama Jakarta Kebayoran Baru Tiga, KPP Pratama Jakarta Kebayoran Baru Empat, KPP Pratama Jakarta Kebayoran Lama, KPP Pratama Jakarta Pesanggrahan, KPP Pratama Jakarta Pasar Minggu, KPP Pratama Jakarta Cilandak dan KPP Pratama Jakarta Jagakarsa.

Microsoft Excel sendiri sudah banyak dimanfaatkan untuk berbagai hal, mulai dari sekedar mengolah data, untuk pembelajaran matematika, hingga digunakan untuk prototype piranti lunak visual (Pane, 2015; Harmastuti \& Setyowati, 2018; Sormin, Sahara \& Agustina, 2018). Begitu juga dengan pelatihan Microsoft Excel sudah dilaksanakan untuk berbagai kalangan seperti siswa sekolah beserta gurunya, kelompok PKK, karyawan, hingga di pemerintahan (Miftakhur Rokhman et al., 2018; Sormin, Sahara \& Agustina, 2018; Petro \& Swatan, 2019; Rahman, Yuridka \& Sari, 2019; Hardiantio Roki, FC, Lucky Lhaura Van, 2019).

\section{METODE PELAKSANAAN}

Pengabdian Kepada Masyarakat ini melewati beberapa tahapan mulai dari penggalian informasi, perencanaan kegiatan, pembuatan materi, pelaksanaan kegiatan, hingga pembuatan laporan. Berikut ini detail metode pelaksanaan:

Observasi 
Setelah mitra memberikan informasi terkait kebutuhannya, pengusul segera melakukan melakukan analisa situasi mitra dengan melakukan observasi terhadap kondisi terkini mitra. Observasi dimulai dari melihat lokasi, profil, produk yang dijual, sampai teknik penjualan serta pemasaran yang dilakukan.

\section{Pengumpulan Data}

Selain menganalisa situasi mitra dengan melihat langsung, pengusul mengumpulkan data untuk dapat dilakukan analisa lebih lanjut. Data yang dikumpulkan diantaranya adalah lokasi mitra, usia calon peserta, tingkat pendidikan calon peserta, serta jumlah calon peserta.

\section{Literatur Review}

Digunakan untuk menggali informasi dari berbagai sumber seperti jurnal, makalah atau referensi lain yang bersifat valid dan relevan. Literature review juga digunakan untuk menggali lebih dalam kebutuhan dan solusi yang dapat dibuat.

\section{Pembuatan Materi}

Setelah dapat menyimpulkan masalah yang dialami mitra dan menemukan solusi yang tepat, maka segera dibuat materi untuk pelatihan. Materi yang dibuat disesuaikan dengan kondisi kebutuhan mitra dan calon peserta yang akan hadir.

\section{Pelaksanaan}

Berikutnya PKM dilaksanakan sesuai dengan jadwal dan lokasi yang sudah disepakati bersama. Pelaksanaan dilakukan di lokasi yang disesuaikan dengan kebutuhan mitra.

\section{Evaluasi}

Setelah kegiatan PKM dilaksanakan, dilakukan evaluasi terhadap hasil pelatihan. Evaluasi dilakukan dengan memberikan soal dan dibandingkan antara jawaban pada soal pre-test dengan post-test.

\section{HASIL DAN PEMBAHASAN}

Kegiatan pengabdian kepada masyarakat ini dilaksanakan pada Selasa, 10 Maret 2020 dan berlangsung pukul 08:00 s/d 16:00 WIB. Lokasi pelaksanaan untuk pelatihan adalah Aula Edisi 35 Lantai 2 Kanwil DJP Jakarta Selatan II Revenue Tower Lot 13 SCBD. Pada kegiatan ini disampaikan materi mengenai bagian-bagian Microsoft Excel, Cara Menjumlahkan dengan Operator Aritmatika, Menggunakan (Rumus), Rumus Excel Dasar, Rumus IF, Rumus VLOOKUP dan HLOOKUP, dan Cara Membuat Chart. 


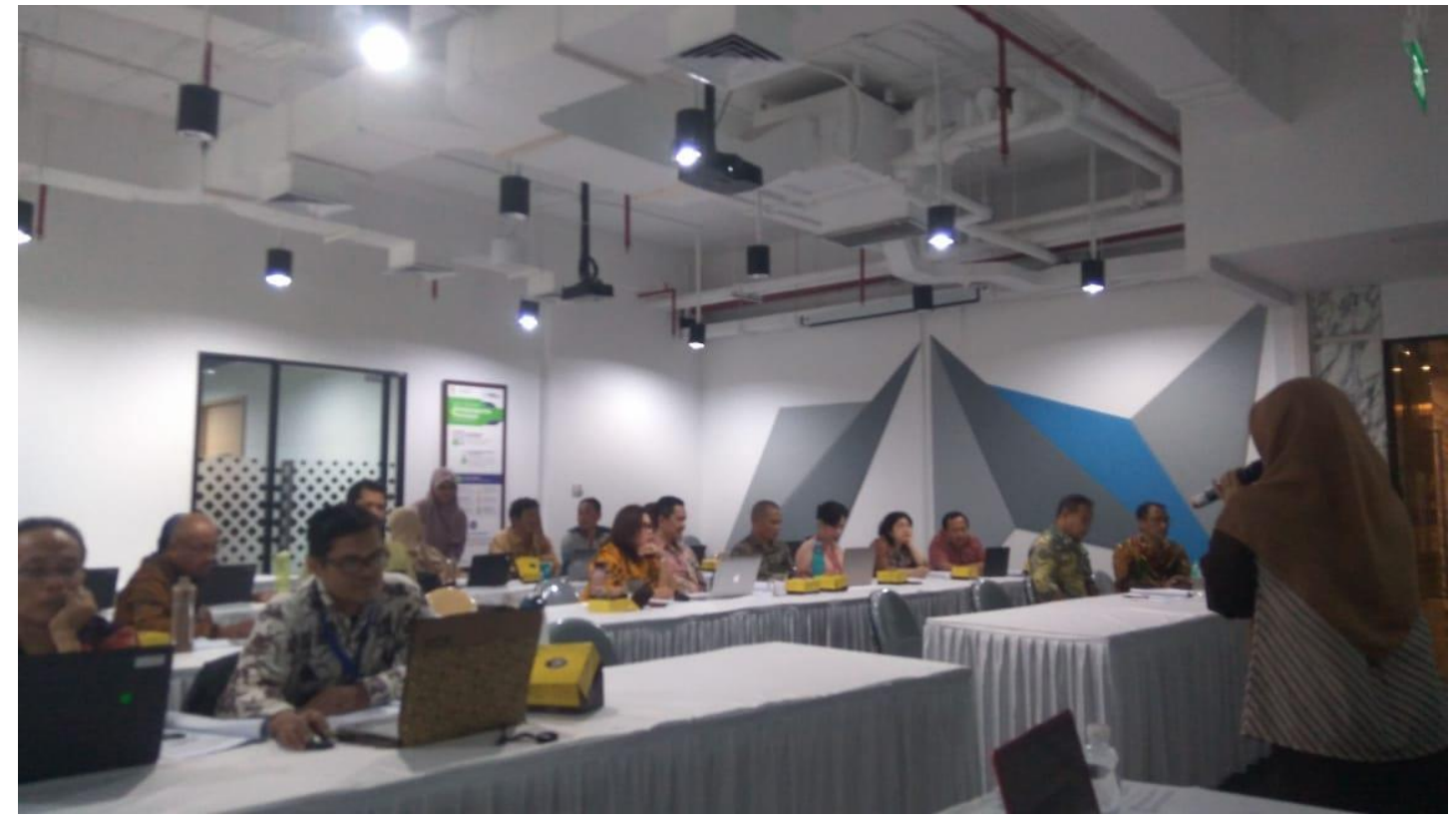

Gambar 2. Instruktur Memberikan Materi Kepada Peserta Pelatihan

Pada Gambar 2. Instruktur pelatihan Ibu Titin Fatimah, S.Kom, M.Kom dan Tim kegiatan PPM menyampaikan materi pelatihan mulai dari fungsi-fungsi dari Ms. Excel yang paling dasar secara bertahap step by step kemudian dilanjutkan ke fungsi-fungsi yang nantinya peserta dapat aplikasikan didalam pekerjaan nya masing-masing hingga peserta dapat membuat Chart atau Grafik.

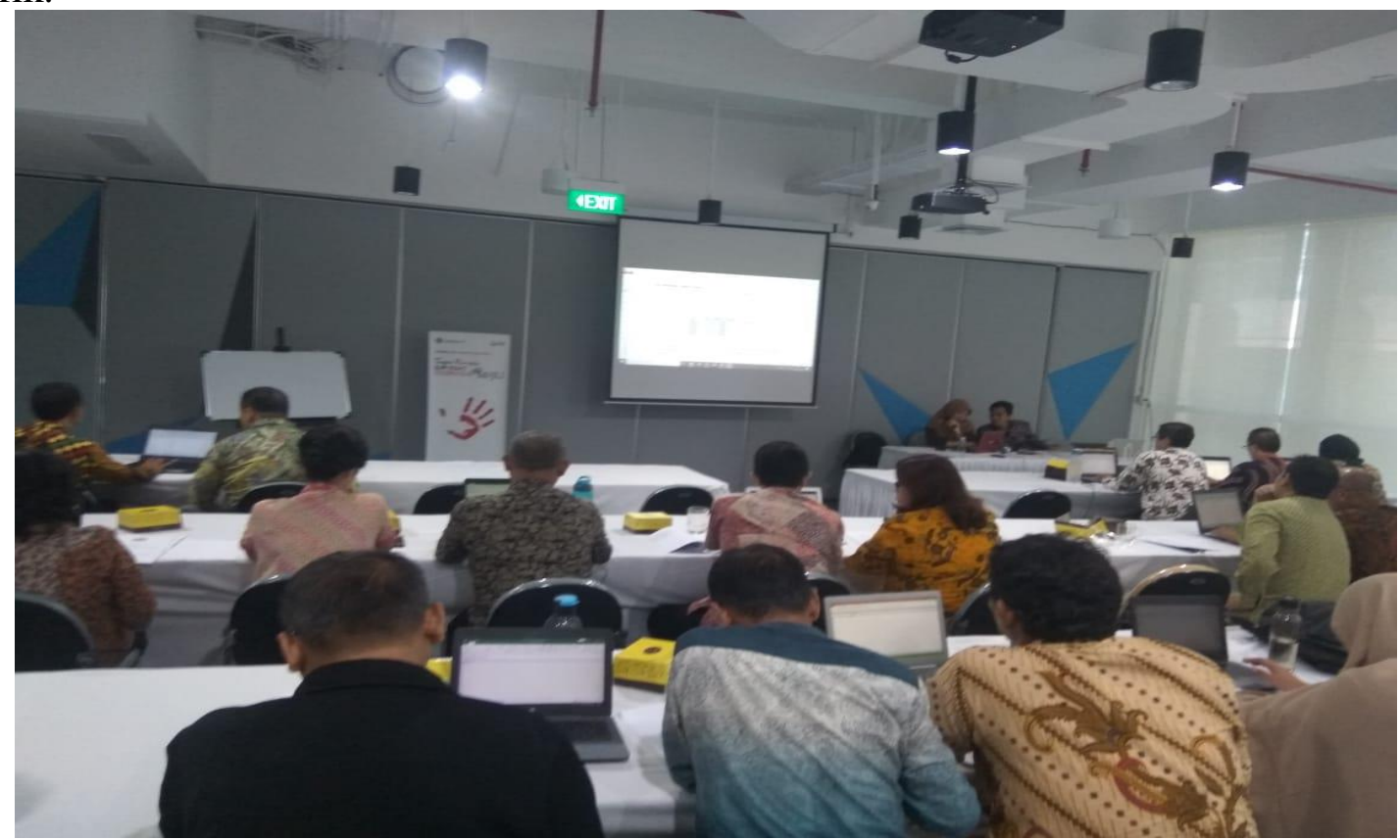

Gambar 3. Peserta Pelatihan Praktik Latihan

Pada Gambar 3. Setelah instruktur menjelaskan materi pelatihan secara bertahap, para peserta pelatihan pun kemudian mempraktikan latihan yang diberikan agar dapat langsung difahami, Asisten Instruktur secara langsung mendampingi dan membantu apabila peserta mengalami kesulitan. 


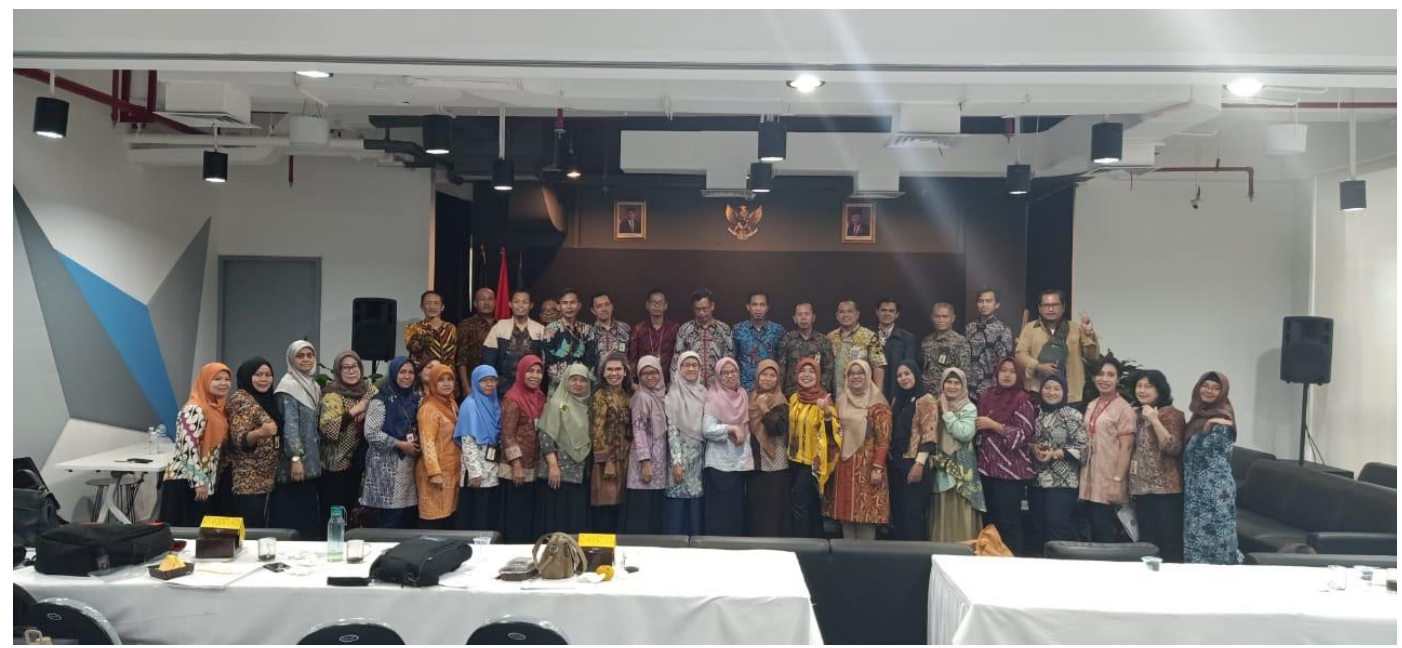

Gambar 4. Foto Bersama Seluruh TIM Kegiatan

Pada Gambar 4, dilakukan foto bersama seluruh Tim Kegiatan Pengabdian kepada Masyarakat dan seluruh peserta pelatihan. Sebelum materi disampaikan peserta diberikan Pre Test dengan format soal pilihan ganda yang terdiri dari 20 pertanyaan dan diikuti oleh 21 orang dari 24 jumlah peserta. Nilai yang diperoleh dapat dilihat pada Tabel 1 berikut ini:

Tabel 1. Tabel Range Nilai Pre Test

\begin{tabular}{|c|c|}
\hline Range Nilai & Jumlah Peserta \\
\hline $0-59$ & 3 \\
\hline $60-79$ & 8 \\
\hline $80-100$ & 10 \\
\hline Total Peserta & $\mathbf{2 1}$ \\
\hline
\end{tabular}

Rincian Range Nilai dapat dilihat pada Gambar 4 dimana Rata-Rata nilai dari Pre Test adalah 72,86 dengan Median adalah 70, nilai terkecil adalah 50, dan nilai terbesar adalah 90.

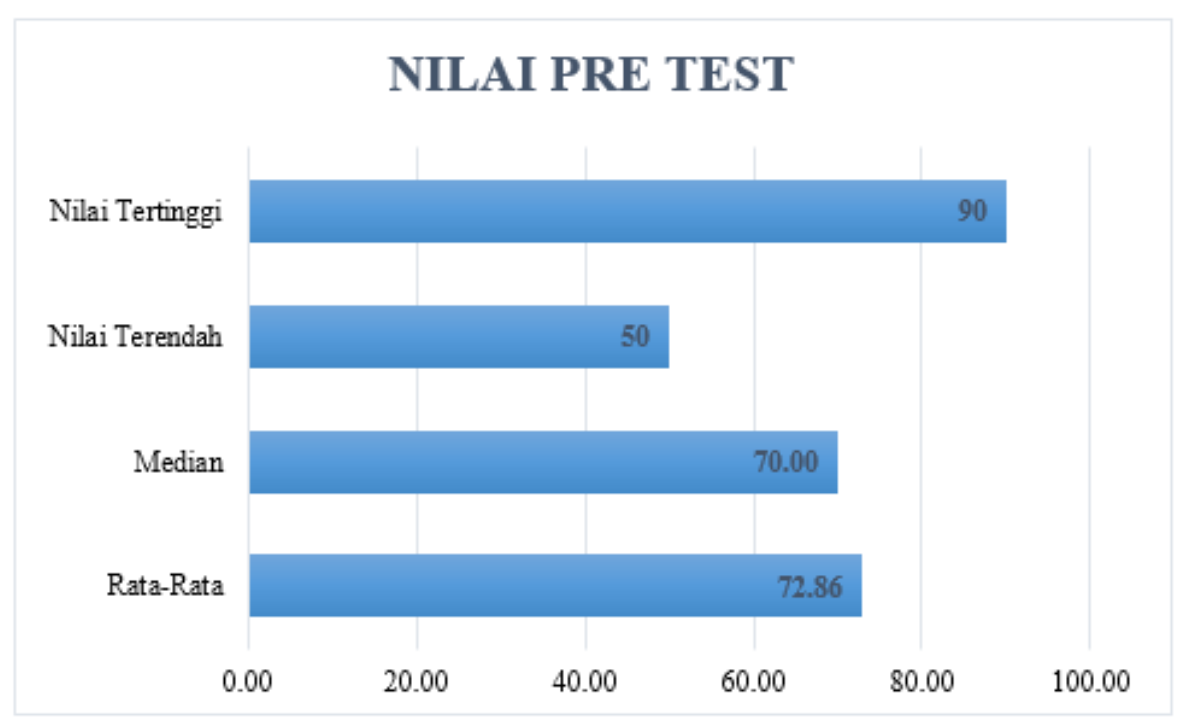

Grafik 1. Grafik Nilai Pre Test 
Diakhir pemberian materi, peserta diberikan lagi Post Test dengan soal yang sama dengan Pre Test. Pemberian soal yang sama untuk melihat apakah materi yang disampaikan diterima oleh peserta. Hasil nilai Post Test dapat dilihat pada Tabel 2 berikut ini:

Tabel 2. Tabel Range Nilai Post Test

\begin{tabular}{|c|c|}
\hline Range Nilai & Jumlah Peserta \\
\hline $0-59$ & 1 \\
\hline $60-79$ & 5 \\
\hline $80-100$ & 18 \\
\hline Total Peserta & $\mathbf{2 4}$ \\
\hline
\end{tabular}

Rincian Range Nilai dapat dilihat pada Gambar 5 dimana rata-rata Post Test adalah 82,5 dengan median adalah 90, nilai terkecil adalah 30, dan nilai terbesar adalah 100.

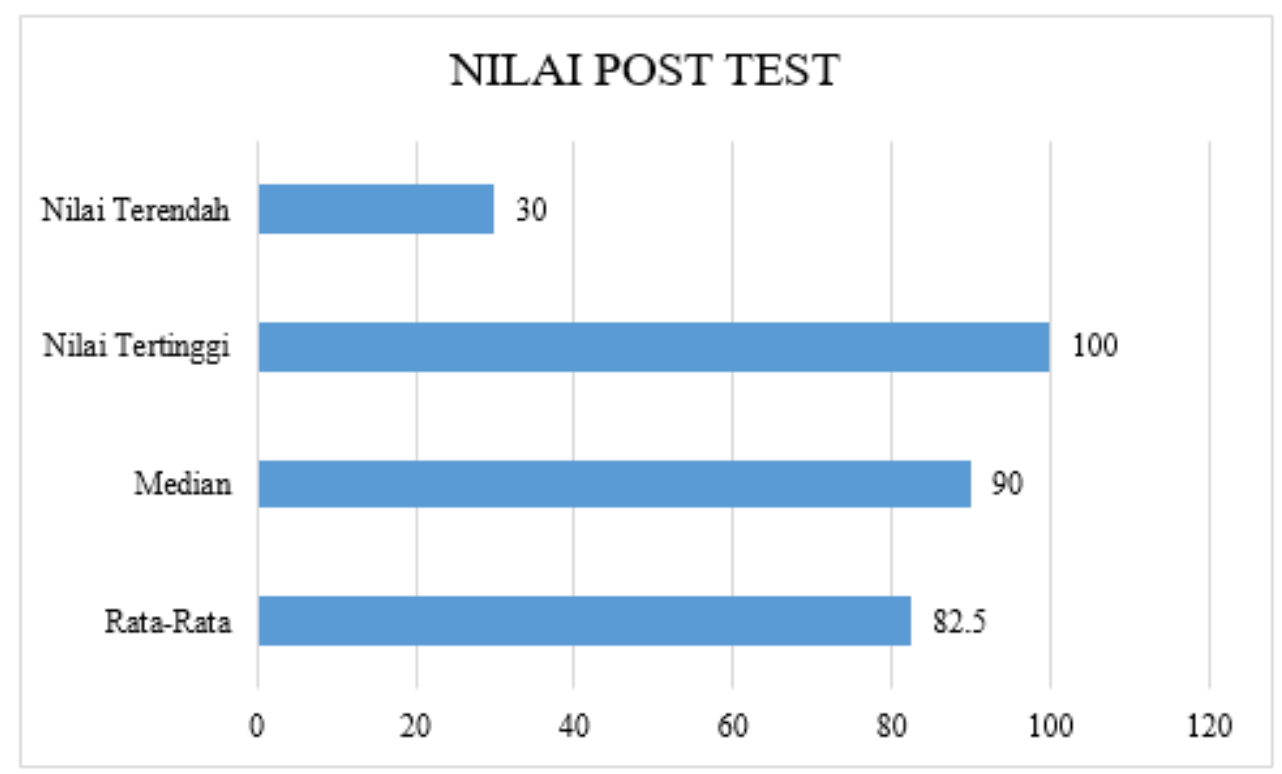

Grafik 2. Grafik Nilai Post Test

Terdapat 3 (tiga) peserta yang tidak mengikuti Pre Test. Berdasarkan pada Tabel 5.3 dan Tabel 5.4 grafik, jumlah peserta yang mempunyai range nilai 0-59 mengalami penurunan sebanyak $66,67 \%$. Jumlah peserta yang mempunyai range nilai 60-79 mengalami penurunan sebanyak $37,5 \%$. Dan jumlah peserta yang mempunyai range nilai 80-100 mengalami kenaikan sebanyak 80\%. Pada Gambar 5.1 dan Gambar 5.2 juga dapat dilihat terdapat kenaikan rata-rata nilai peserta dari 72,86 menjadi 82,5 . Dapat disimpulkan pemahaman peserta mengenai materi pelatihan mengalami peningkatan dari hasil test yang telah dilakukan.

Dapat disimpulkan pemahaman peserta mengenai materi pelatihan mengalami peningkatan dari hasil test yang telah dilakukan.

\section{KESIMPULAN DAN SARAN}

Pada pelatihan yang telah dilaksanakan para peserta berhasil menggunakan workbook dan worksheet pada Excel; membuat tabel, menyajikan data dengan fungsi rumus dasar excel, rumus IF, fungsi Vlookup, serta fungsi Hlookup; membuat chart; dan mencetak dokumen dari 
file excel. Dilihat dari hasil Pre Test dan Post Test menandakan bahwa bahwa peserta pada awalnya sudah cukup mengenal lingkungan workbook dan worksheet Excel dengan baik apalagi jika hanya menggunakan fungsi Excel dasar. Para peserta hanya perlu lebih terbiasa menggunakan fungsi-fungsi yang disediakan Excel dalam mendukung pekerjaan terutama dalam menyajikan data dengan tabulasi.

Agar mencapai sasaran yang maksimal maka diperlukan kerjasama lanjutan terkait pemanfaatan teknologi Microsoft Office Excel. Kegiatan yang disarankan seperti meningkatkan soft skill dari peserta dalam mengembangkan soft skill dalam penggunaan fungsi pada Microsoft Excel seperti Range Name Static dan Dynamic, Hyperlink, Multiple Worksheet dan Workbook, Index Match Function, Filtering Data, Subtotal Function, Data Validation, dan Conditional Formatin, dan lain-lain.

\section{UCAPAN TERIMA KASIH}

Penulis mengucapkan terima kasih kepada Fakultas Teknologi Informasi Universitas Budi Luhur dan Direktorat Jendral Pajak (DJP) yang telah memberi dukungan pembiayaan terhadap pengabdian masyarakat ini serta ucapan terima kasih terhadap atensi Pegawai Kanwil DJP Jakarta Selatan II dan seluruh panitia pelaksanaan, sehingga seluruh kegiatan dapat terlaksana dengan baik dan lancar.

\section{DAFTAR PUSTAKA}

Direktorat Jenderal Pajak. (2019). Laporan Kinerja Direktorat Jenderal Pajak Tahun 2019. Kementerian Keuangan Republik Indonesia Direktorat Jendral Pajak.

Hardiantio Roki, FC, Lucky Lhaura Van, \& F. W. (2019). Pelatihan Office Perkantoran Di Sma Pgri Pekanbaru Sebagai Bekal Menyonsong Revolusi Industri 4.0. DINAMISIAJurnal Pengabdian Kepada Masyarakat, 3(1), 53-61.

Harmastuti, \& Setyowati, D. (2018). Pemanfaatan Microsoft Excel Untuk Pembelajaran Matematika Dan Grafik. Dharma Bakti, 1(1), 57-66.

Pane, I. Z. (2015). Pemanfaatan Microsoft Excel Sebagai Perangkat Pengembangan Prototipe Piranti Lunak Visual. Jurnal ULTIMA InfoSys, 6(1), 20-26.

Petro, S., \& Swatan, K. H. (2019). Pelatihan Microsoft Excel Sebagai Penunjang Ketrampilan Hard Skill Bagi Siswa Pada Smk Ypsei Palangka Raya. Jurnal Abdimas BSI: Jurnal Pengabdian Kepada Masyarakat, 2(2), 280-286.

Rahman, A., Yuridka, F., \& Sari, M. (2015). Pelatihan Komputer Program Microsoft Excel 2013 pada SMAN 12 Banjarmasin. Journal of Chemical Information and Modeling, 1(1), 5-10.

Rokhman, Miftakhur, M., Adi Wibowo, S., Agus Pranoto, Y., \& Ardi Widodo, K. (2018). Pelatihan Pemanfaatan Microsoft Office Pada Staf Pengajar Di SMPLBN (Sekolah Menengah Pertama Luar Biasa Negeri) Kota Malang. Jurnal Mnemonic, 1(1), 4-9.

Rysaka, N., Saleh, C., \& Rengu, S. P. (2014). Penerapan Sistem Elektronik Dalam Pelayanan Perpajakan (Studi Pada Kantor Pelayanan Pajak Pratama Malang Utara). Jurnal Administrasi Publik Mahasiswa Universitas Brawijaya, 2(3), 420-425.

Sormin, M. A., Sahara, N., \& Agustina, L. (2018). Pelatihan Pemanfaatan Perangkat Lunak (Microsoft Office Word, Excel, Power Point) Dalam Kinerja Pengolahan Data Di Pemerintahan Desa Bagikepala Desa Se-Kecamatan Batang Angkola. Martabe: Jurnal Pengabdian Kepada Masyarakat, 1(2), 78-82.

Wardani, R. T. I. (2017). Pelatihan Aplikasi MS Excel Untuk Efisiensi Pengelolaan Siswa Pada Guru SMPK. Jurnal Abdimas Politeknik Negeri Malang, 4(1), 68-75. 